Editorial

\title{
Understanding the Lack of Under-represented Racial and Ethnic Minorities in Ophthalmology
}

\author{
Emily K. Tam, MD, MPH ${ }^{1}$ Michael Harrell, MD ${ }^{1} \quad$ Nicole H. Siegel, MD ${ }^{1}$ \\ ${ }^{1}$ Department of Ophthalmology, Boston University Medical Center, \\ Boston, Massachusetts \\ J Acad Ophthalmol 2021;13:e192-e194.
}

To adequately address the racial and ethnic disparities in eye care for our increasingly diverse society there needs to be a significant increase in physicians from under-represented minority groups (URMs) who pursue careers in ophthalmology. Studies have shown that patient-physician racial congruence tends to improve patient satisfaction and medical compliance. ${ }^{1}$ However, there are significant racial and ethnic disparities that exist within medicine as a whole and, more specifically, within the field of ophthalmology. ${ }^{2}$ One way to address this gap is to diversify the physician workforce by increasing the number of physicians from URMs. ${ }^{2}$ URM is defined by membership in certain ethnic and racial minority groups (i.e., Black, Hispanic, American-Indian, Alaskan Native, Native Hawaiian, and Pacific Islander). These ethnic/ racial minority groups have been deemed underrepresented in medicine (URiM). ${ }^{3}$ According to recent United States (U.S.) Census data, URM groups comprise $30.7 \%$ of the American population. ${ }^{3}$ However, a study published in 2016 based on information from the U.S. Census, Association of American Medical Colleges (AAMC), and the American Medical Association (AMA), found that only $6 \%$ of practicing ophthalmologists were from URM minority groups (3.3\% Hispanic, 2.5\% Black, and $0.2 \%$ Native American). ${ }^{3}$ Fairless et al reviewed the medical school faculty demographic data from the 2019 American Association of Medical Colleges Faculty Roster and discovered that ophthalmology has the third lowest proportion of URM faculty within all clinical departments at U.S. medical schools. ${ }^{4}$ Similarly, URiM trainees comprise only $7.7 \%$ of ophthalmology residents across the country, a figure that has been essentially stagnant, despite widespread efforts to increase URM matriculants in medical schools. ${ }^{3} \mathrm{~A}$ recent call to action highlighted the significant need to increase the number of URiMs within ophthalmology training programs, academic institutions, and private practices. ${ }^{2}$
Here, we explore potential explanations for the low numbers of URMs in ophthalmology, in an effort to provide insights to improve the diversity of the ophthalmology workforce.

One proposed explanation for a lack of ophthalmologists in training programs, and ultimately practicing ophthalmologists, stems from a lack of role models and mentors within the field of ophthalmology. Studies have consistently demonstrated that role models have the capacity to significantly influence the specialty, or subspecialty, that their mentees ultimately choose. ${ }^{2}$ According to a published report on science, technology, engineering, and mathematics (STEM) program at University of North Carolina at Chapel Hill (UNC$\mathrm{CH}$ ), URM students view "advisors," as those who they sought out for advice but with whom they remained more distant and less involved. ${ }^{5}$ However, the URM students view "mentors" as those who help students not only in academics and research, but also who inspire them through their shared personal, such as ethnic or gender, identity. ${ }^{5}$ Given that URMs comprise only $6 \%$ of practicing ophthalmologists, it would be much less likely for a URM mentee to be exposed to a URM ophthalmologist at their medical schools and within their communities to serve as a potential race-concordant mentor. ${ }^{3,6}$ Concurrently, the proportion of URMs among ophthalmology faculty has decreased over the past decade (from 6.2 to $5.7 \% ; p=00.01)^{2,3}$ The lack of both early exposure and adequate mentorship within the field may further decrease one's chance of choosing to pursue and successfully matching into an ophthalmology residency, which are notoriously competitive. More opportunities to expose URM medical students to ophthalmology at an earlier stage of their training are needed. This can be partially achieved by involvement of cross-cultural, or race-discordant mentors. ${ }^{6}$ Limited data exists about the benefit of raceconcordant versus race-discordant mentoring relationships.
Address for correspondence

Nicole Siegel, MD, 85 E. Concord

St., $8^{\text {th }}$ Floor, Boston, MA 02118

(e-mail: nicole.siegel@bmc.org).
DOI https://doi.org/

10.1055/s-0041-1736495.

ISSN 2475-4757. (c) 2021. The Author(s).

This is an open access article published by Thieme under the terms of the Creative Commons Attribution-NonDerivative-NonCommercial-License, permitting copying and reproduction so long as the original work is given appropriate credit. Contents may not be used for commercial purposes, or adapted, remixed, transformed or built upon. (https://creativecommons.org/ licenses/by-nc-nd/4.0/)

Thieme Medical Publishers, Inc., 333 Seventh Avenue, 18th Floor, New York, NY 10001, USA 
Recognizing the importance of this problem, there have been many programs developed within the field of ophthalmology to help to increase the early exposure and all mentorship for URM medical students. The Minority Ophthalmology Mentoring program, a newer initiative established in partnership with the American Academy of Ophthalmology and the Association of University Professors of Ophthalmology, aims to increase URM medical students' exposure to the field of ophthalmology. ${ }^{7}$ The impact of this program needs to be evaluated over time to determine its ability to effect change.

Another explanation for the paucity of URMs in ophthalmology is due to the limited number of URMs in medicine, as a whole, which translates into an even smaller percentage opting to pursue a career in ophthalmology. ${ }^{8}$ In 2019, only approximately $13 \%$ of physicians were from URM groups, whereas $31 \%$ of the U.S. population identify with one or more URM groups. ${ }^{3}$ According to the American Medical Association, there were 38,376 applicants for 35,185 total positions into U.S. residency positions. ${ }^{9}$ However, in the same year, only 512 U.S. allopathic medical school seniors out of 38,376 (1.3\%) applied for an ophthalmology residency. ${ }^{9,10}$ In 2021, only $74 \%$ of the medical students who applied, matched into one of the 499 available ophthalmology residency spots, confirming the competitive nature of securing a spot within an ophthalmology residency program. ${ }^{10}$ Ophthalmology is not prominently included within the medical school curriculum during the first and second years and, at most schools, is not a required rotation during third year clerkships. As a result, early exposure, even by a chance encounter, during high school, college or early on during medical school can become hugely important to pique one's interest in the field.

The problem is compounded by the fact that there is a higher probability of Black males attending under-performing schools that lack comprehensive premedical resources, making it more difficult for students to successfully apply to medical school. ${ }^{11}$ The AAMC reported an alarming 35-year decline in Black males pursuing careers in medicine. ${ }^{11}$ Over the same time course, the Black population has experienced poorer health outcomes compared with their White counterparts in the United States. ${ }^{12}$ One way to address this is to have early initiatives starting in high school or college to expose students to medical careers earlier during their schooling. Additionally, giving more support to Historically Black Colleges and Universities (HBCU) could become very valuable, as HBCUs have graduated more Black doctors over the past 10 years than the top 10 predominantly White schools, combined. $^{13}$

Lastly, the financial cost of pursuing a medical career can be a significant deterrent to URM students and this impact may be more dramatic for Black Americans, given the higher proportions of unemployment rates within the community. ${ }^{14,15}$ According to a qualitative study on Black high school students in a Milwaukee Public High School, it was identified that financial constraints contribute to significant barriers to pursuing medical careers. ${ }^{16}$ The Guardian reports that half of Black college students graduate with more than $\$ 25,000$ in student loan debt. ${ }^{17}$ According to a report by educationdata.org, in the United States, $40 \%$ of Black graduates have student loan debt from graduate school compared with $22 \%$ of White college graduates. ${ }^{18}$ The 2018 U.S. census data reports that Native Americans, Blacks, and Hispanics have the highest poverty rates at 25.4, 20.8 , and $17.6 \%$, respectively, compared with $10.1 \%$ of their White counterparts, which contribute to the racial and ethnic disparities seen within medicine given aforementioned barriers. $^{19}$

There are likely cultural differences that contribute to and help to understand educational disparities. ${ }^{20}$ In one study, Latino youths were less likely to picture themselves attending college but instead saw themselves starting a family, which may lead to a lower socioeconomic status. ${ }^{21}$ For Black students, there were also reported negative social pressures and risks of being accused of "acting White" for one's educational achievements, which could act to deter a student from being successful in school. ${ }^{21}$ Programs such as the Robert Wood Johnson Foundation have been successful in supporting minority students in going to medical schools and increasing diversity in the health professions. ${ }^{22}$ There needs to be more financial support such as longitudinal scholarships, travel grants, and housing stipends to support URMs with interests in medicine and provide them with earlier exposure to the field of ophthalmology. While there are many potential root causes to this problem, there are potential ways to help increase the number of URMs within the field of ophthalmology. Early exposure, such as outreach in diversity and inclusion college programs may increase awareness to ophthalmology among URM college students. There are already limited ophthalmology programs; similarly, medical students' exposure to ophthalmology is becoming more limited in most medical schools, and the number of medical schools requiring a formal ophthalmology rotation has declined over the years. ${ }^{23}$ Perhaps, ophthalmology academic departments could team-up with ophthalmology special interest groups within the medical schools to present lectures and case presentations to first and second year medical students to help pique the students' interests in the field. ${ }^{23}$ Meanwhile, it is important to recruit non-URM ophthalmology faculty to mentor URM students to help improve diversity in ophthalmology. ${ }^{6}$ According to a systemic review, mentorship of URM students can be effective even if the mentor is not from the same background. ${ }^{24}$ We hope that this article is the first step, of many, to explore reasons why there is a lack of URM trainees in ophthalmology with the goal to have medical doctors and ophthalmologists more accurately reflect the diversity that exists within the population of the United States to be able to achieve the best health outcomes. Additionally, we hope that our suggestions may help to improve both the number of URMs in ophthalmology training programs as well as those practicing as ophthalmologists in the United States.

Conflict of Interest

None declared. 


\section{References}

1 Kerse N, Buetow S, Mainous AG III, Young G, Coster G, Arroll B. Physician-patient relationship and medication compliance: a primary care investigation. Ann Fam Med 2004;2(05):455-461

2 Aguwa UT, Srikumaran D, Brown N, Woreta F. Improving racial diversity in the ophthalmology workforce: a call to action for leaders in ophthalmology. Am J Ophthalmol 2021;223:306-307

3 Xierali IM, Nivet MA, Wilson MR. Current and future status of diversity in ophthalmologist workforce. JAMA Ophthalmol 2016; 134(09):1016-1023

4 Fairless EA, Nwanyanwu KH, Forster SH, Teng CC. Ophthalmology Departments Remain Among the Least Diverse Clinical Departments at United States Medical Schools. Ophthalmology 2021 Aug;128(08):1129-1134

5 Atkins K, Dougan BM, Dromgold-Sermen MS, Potter H, Sathy V, Panter AT. "Looking at Myself in the Future": how mentoring shapes scientific identity for STEM students from underrepresented groups. Int J STEM Educ 2020;7(01):42

6 Campbell KM. The diversity efforts disparity in academic medicine. Int J Environ Res Public Health 2021;18(09):4529

7 American Academy of Ophthalmology. Minority Ophthalmology Mentoring. Published 2021. Accessed January 20, 2021 at: https://www.aao.org/minority-mentoring

8 Grubbs JR, Mian SI. Advising students interested in ophthalmology: a summary of the evidence. Ophthalmology 2016;123(07): 1406-1410

9 Murphy B. Inside the numbers behind the record-setting 2019 Match. March 3, 2020. Accessed December 20, 2020 at: https:// www.ama-assn.org/residents-students/match/inside-numbersbehind-record-setting-2019-match

10 SF Match. Ophthalmology Residency Match Summary Report. Accessed October 7, 2021 at: https://gme.medicine.uiowa.edu/ sites/gme.medicine.uiowa.edu/files/wysiwyg_uploads/2017\%200 phthalmology\%20Residency\%20Match.pdf

11 Laurencin CT, Murray M. An American Crisis: the lack of Black Men in medicine. J Racial Ethn Health Disparities 2017;4(03):317-321

12 Armstrong K, Ravenell KL, McMurphy S, Putt M. Racial/ethnic differences in physician distrust in the United States. Am J Public Health 2007;97(07):1283-1289

13 Gasman M, Smith T, Ye C, Nguyen TH. HBCUs and the production of doctors. AIMS Public Health 2017;4(06):579-589
14 Noonan AS, Velasco-Mondragon HE, Wagner FA. Improving the health of African Americans in the USA: an overdue opportunity for social justice. Public Health Rev 2016;37:12

15 BLS. Labor force characteristics by race and ethnicity, 2018. October 2019. Accessed December 20, 2020 at: https://www. bls.gov/opub/reports/race-and-ethnicity/2018/home.htm

16 Rao V, Flores G. Why aren't there more African-American physicians? A qualitative study and exploratory inquiry of AfricanAmerican students' perspectives on careers in medicine. J Natl Med Assoc 2007;99(09):986-993

17 Kasperkevic J. Half of black college students graduate with more than $\$ 25,000$ in student loan debt. The Guardian. October 17 , 2014. Accessed December 20, 2020 at: https://www.theguardian. com/money/us-money-blog/2014/oct/07/expensive-college-education-reinforces-racial-inequality-us-america

18 Educationdata.org. Student Loan Debt by Race. Published September 24, 2020. Accessed January 20, 2021 at: https:// educationdata.org/student-loan-debt-by-race

19 Creamer J. Inequalities Persist Despite Decline in Poverty For All Major Race and Hsipanic Origin Groups. Published September 15 2020. Accessed January 20, 2021 at: https://www.census.gov/ library/stories/2020/09/poverty-rates-for-blacks-and-hispanicsreached-historic-lows-in-2019.html

20 Turcios-Cotto VY, Milan S. Racial/Ethnic differences in the educational expectations of adolescents: does pursuing higher education mean something different to latino students compared to white and black students? J Youth Adolesc 2013;42(09): 1399-1412

21 Pechura CM. Programs of the Robert Wood Johnson Foundation to develop minority medical careers. Am J Med Sci 2001;322(05): 290-292

22 Quillen DA, Harper RA, Haik BG. Medical student education in ophthalmology: crisis and opportunity. Ophthalmology 2005; 112(11):1867-1868

23 Patel MS, Mowlds DS, Khalsa B, et al. Early intervention to promote medical student interest in surgery and the surgical subspecialties. J Surg Educ 2013;70(01):81-86

24 Bonifacino E, Ufomata EO, Farkas AH, Turner R, Corbelli JA. Mentorship of underrepresented physicians and trainees in academic medicine: a systematic review. J Gen Intern Med 2021;36 (04):1023-1034 